\title{
La ley del deseo como esencia ética de lo político
}

\section{The law of desire as the ethical essence of the political}

\author{
ROQUE FARRÁN \\ (UNC/Conicet)
}

\begin{abstract}
RESUMEN. En el presente artículo me propongo interrogar el estatuto ético-político de la ley en su diferencia ontológica respecto a lo meramente normativo o contable, para ello comento algunos aportes teóricos de autores como Alain Badiou, Jacques Rancière, Jacques Lacan, Giorgio Agamben, Slavoj Zizek, Jean-Luc Nancy y Roland Barthes, que nos permitirán pensar más acá de lo discernible por el lenguaje establecido. La idea principal que conlleva el cruce de estas referencias afines aunque disímiles, es la de circunscribir el acto fugaz de afirmación de la ley qua diferencia que habilita la constitución de un sujeto político, remarcando así su dimensión esencialmente ética.
\end{abstract}

Palabras clave: Ley, deseo, ética, política, acontecimiento, sujeto.
ABSTRACT. In this article I propose to interrogate the ethical - political statute of the law in its ontological difference concerning the merely normative or countable thing.In order to do that I comment some theoretical contributions of Alain Badiou, Jacques Rancière, Jacques Lacan, Giorgio Agamben, Slavoj Zizek, Jean - Luc Nancy and Roland Barthes, that allow us to think closer than the discernible by the language. The main idea that involves the crossing of these affine references is to circumscribe the fleeting act of affirmation of the law qua difference that enables the constitution of a political subject remarking its essentially ethical dimension.

Key words: Law, desire, ethics, politics, event, subject.

«(...) si un hombre pudiera escribir un libro de ética que realmente fuera un libro de ética, ese libro destruiría, como una explosión todos los demás libros del mundo».

L. Wittgenstein

¿Se puede pensar sin querer definir antes las condiciones de posibilidad del pensamiento? ¿Recuerdan la burla de Hegel, dirigida por elevación a Kant, hacia aquellos que querían - y aún hoy: quieren - aprender a nadar antes de lanzarse al agua? ¿Pensar directamente sin a prioris ni criterios de verdad, es posible? 
El buen método, decía Spinoza, no precede al conocimiento, es interior a él; la idea de la idea - la reflexión, el método - requiere partir de una idea verdadera, la cual es tanto signo de sí misma como de lo falso. Cuando se parte de ahí se trata de producir, de extraer consecuencias de ello y punto (indagaciones efectivas). Por eso me gustaría sugerir una inversión a la doxa que sostiene que la teoría (la filosofía) es per se idealista y especulativa mientras que la política es, en cambio, práctica y activa. Al contrario, sostengo que incluso en la teoría puede haber pensamiento - aunque no sea tan frecuente-, que incluso en la filosofía puede haber materialidad, que por extraño que parezca puede haber allí mismo un grano de real; mientras que la política puede estar dominada por algún filosofema, explícito o no, que la vuelve repetitiva e inútil. Claro, esto no va de suyo, hay que trabajar sobre los conceptos bajo condiciones específicas para que algo material precipite, para que algo anude imprevistamente.

Sin embargo, para que algo de ello acontezca es preciso interrumpir o suspender cualquier prescripción normativa, cualquier estándar fijo o protocolo de producción ${ }^{1}$. No hay garantías ni criterios de verdad en una práctica materialista verdadera. Distinguimos aquí, junto a Althusser, práctica política de práctica teórica; ambas no se confunden aunque haya una dimensión de lo político en la teoría (es lo que sostenemos) y de ésta en aquélla. No obstante, no toda práctica teórica indaga su dimensión política (polémica). Adelanto entonces dos tesis (post) althusserianas que orientan mi trabajo.

Primera tesis. La especificidad de la filosofía o práctica teórica es la de producir vacío. El vacío se genera a partir de conceptos. ¿Cómo es eso? Pues bien, nos inscribimos en una perspectiva de crítica materialista, lo cual implica para nosotros mostrar, al modo de Marx y Althusser, que hay vacíos en lo pleno del discurso. Eso nos encauza, nos pone a trabajar.

Segunda tesis. Toda práctica posee una cobertura ideológica/imaginaria de significaciones estañadas que tiende a obturar su vacuidad/simbólica de base y a producir una suerte de hipóstasis o fijación de $-\mathrm{y}$ en - sus propios términos y procedimientos, llámesele a esto «filosofía espontánea de los sabios», «concepción de mundo», «racionalización», «mistificación», o cualquier otra. Incluso si se dice muy posmodernamente hablando $-\mathrm{y}$ ésta es

1 Si consideramos nuestra propia práctica teórica como «material» e «histórica», el valor de la interrupción, el intervalo, resulta aquí crucial; como escribe Agamben respecto a la historia: «Por eso la historia no puede ser el progreso continuo de la humanidad hablante a lo largo del tiempo lineal, sino que es esencialmente intervalo, discontinuidad, epokhé.» (Agamben, Giorgio, Infancia e historia, Adriana Hidalgo, Buenos Aires, 2007, p. 74). Nos inscribimos en esta posición teórica, donde la historicidad es asumida intrínsecamente como disyunción o intervalo (la ley qua diferencia), en lugar de remitirla a un contexto de significación global cuya ficción de completud daría un efecto imaginario de continuidad. En este sentido, nuestras tesis no pretenden ser originales sino seguir esta tradición soterrada de pensamiento materialista (gracias al informador anónimo por permitirme aclarar este punto entre otros). 
quizás la peor de todas- que no hay tal visión y que «todo» es, más bien, particular y diverso.

«El vacío de una distancia tomada» ${ }^{2}$, al que hacía alusión Althusser en relación a Maquiavelo, exige de nuestra parte una producción teórica específica. Ahora bien, en términos de Badiou - aunque él no lo diga así explícitamente - esto implica lidiar con tres modalidades diferentes de vacío, en tres ámbitos del pensamiento: 1) encontramos el vacío ontológico en el discurso matemático (múltiples puros o inconsistentes) y 2) el vacío óntico en la retroactividad de intervenciones que nombran el exceso in-contado de una situación en el arte, la ciencia, la política o el amor. A su vez ese doble vacío (ontológico y óntico) es circunscrito y conectado por 3) los distintos conceptos filosóficos (vacíos por excelencia), pues recurrentemente se olvida su estatuto de vacuidad y nuevas hipóstasis (racionalizaciones, ideologías) vienen a recubrir el lugar de la falta producida. Así, dos vías simultáneas se habilitan: a) la de las producciones originales en cada ámbito de saber, que agujerean continuamente las estabilizaciones de los mismos (lo cual suele ser encubierto por sujetos reactivos de esos ámbitos), y b) la de las combinaciones posibles (transferencias, correlatos, homologías) entre distintos modos de producción o procedimientos genéricos de verdad ${ }^{3}$. Se evita entonces el imperio de un solo modo de pensamiento y se posibilita, asimismo, la producción múltiple y conjunta de procedimientos. Hay que aclarar, además, que las matemáticas no constituyen modelos fijos de pensamiento, simplemente dada su singular historicidad nos brindan recursos simbólicos para conectar las diversas temporalidades de los acontecimientos, tarea incesante de la producción filosófica. De este modo podemos romper continuamente con las hipóstasis imaginarias de la ley simbólica, que tiende a fijarse - a ser fijada- en significaciones comunes. En definitiva, nuestra tarea de producción conceptual implica reanudar incesantemente las producciones de pensamiento heterogéneas activas en nuestra época. Esta tarea implica a su vez una dimensión ética insoslayable pues requiere impedir constantemente la captura o totalización de una modalidad de la praxis sobre las otras. Pasaré a comentar a continuación cómo se pone en juego esta dimensión ético-política de la práctica teórica en diversos autores, cuyas diferencias aparentes no impiden apreciar la afinidad que, en este sentido, circula entre ellos.

2 Althusser, Louis, La única tradición materialista (en línea www.youkali.com): Youkali n. ${ }^{\circ} 4$, p. 132.

3 Así les llama Badiou a las «condiciones históricas» de la filosofía; arte, ciencia, amor y política. 
Badiou fundamenta su sistema filosófico en una ontología de lo múltiple puro (teoría de los conjuntos ZF) en la que diferencia explícitamente aquello que adviene del ser a la presentación (lo múltiple) de lo que estructura dicha presentación: cuenta-por-uno, ley o estructura. Se trata de una decisión de estatuto ontológico en la que opta por des-identificar al ser con lo Uno y conceptualizar a éste como operación y resultado de cuenta.

Toda situación está estructurada en función de su propia ley (intrínseca) de cuenta-por-uno, por lo tanto lo múltiple en sí, inconsistente, sólo puede suponerse retroactivamente antes de que opere la cuenta, ya que todo lo que se nos presenta en situación son múltiples-unos consistentes (discernibles). Dice Badiou: «Llamo situación a toda multiplicidad presentada. Siendo la presentación efectiva, una situación es el lugar del tener-lugar, cualesquiera sean los términos de la multiplicidad implicada.» ${ }^{4}$

Hasta aquí Badiou al pie de la letra. Ahora pasaré a formular el concepto de ley de una manera más amplia, que nos permitirá pensar la dimensión intrínseca de apertura (deseo) que entraña la ley en su relación compleja con los conceptos de acontecimiento, norma y sujeto. Pues sostengo que es en su mutua imbricación donde se encuentra —el locus - la singular historicidad que los constituye qua conceptos.

La ley para funcionar como tal debe ser aplicada sobre algo. Ésta quizás sea la constatación más obvia, la primera diferencia (ley/objeto), pues si aquélla se aplicara sin más sobre sí misma ipso facto se anularía o destruiría. En efecto, es algo que se sigue de la sola naturaleza interdictora de la ley, independientemente de su contenido o aplicación específicos: en el momento de prohibirse a sí misma se neutraliza ${ }^{5}$.

Ahora bien, pareciera que para constituirse como tal la ley debe fundarse en una exclusión «primitiva», que en realidad es una auto-exclusión; es decir: se excluye de sí abriendo en ese mismo movimiento un hiato o distancia interna que se configura de este modo como su reverso impensado. Pero este

4 A. Badiou, El ser, p. 34.

5 Así lo expresa Derrida: «La ley es prohibición: esto no significa que prohíba sino que ella misma está prohibida, que es un lugar prohibido [...] no se puede alcanzar la ley y para mantener una relación de respeto con ella uno debe interrumpir esa relación. Se debe entrar en relación sólo con los representantes de la ley, sus ejemplos, sus guardianes. Son obstáculos tanto como mensajeros. No debe saberse quién, qué o dónde está la ley.» (Jacques Derrida, Acts of literatura, Nueva Cork, Routledge, 1992, p. 201, citado por S. Zizek en Visiones de paralaje, FCE, Bs. As., 2006, p. 62). El tratamiento que se da aquí al concepto de ley es eminentemente filosófico y está definido en función de la red de conceptos desplegados parcialmente: sujeto, acontecimiento, norma, etc.; por ello no se alude a la tradición canónica del derecho ni a contextos de significación más amplios (i.e. teoría política) que diluirían la especificidad de la intervención teórica esgrimida en el juego entre estos autores singulares. La temática vinculada al derecho está extensamente trabajada por Agamben en su libro Estado de excepción. 
reverso no es nada sustancial — como hemos anticipado - sino la propia ley en su pura diferencia de sí: el vacío tautológico de una aplicación imposible ad initium.

Para garantizar esta distancia interna a la ley, se producen la norma (o patrón) y la aplicación (o interpretación), que dan figura e imaginarizan lo excluido o incontado (la ley misma en su reverso). Figuras de lo imaginario, de la significación, de la valoración y la hipóstasis. Figuras también del cierre, del ordenamiento y la clasificación. Y por supuesto, todo el cortejo correlativo de funcionarios, intérpretes, sacerdotes y profesores que regulan la validez de todo dicho.

La ley, como pura presentación de lo múltiple, está esencialmente abierta; el cierre es más bien ilusorio, producto de la necesidad de significación o representación; y la totalidad es, como se sabe, mítica. Así, por ejemplo en el célebre cuento de Kafka «Ante las puertas de la ley» la pregunta dirigida al guardia (la suposición de saber a un sujeto) cierra ficticiamente las puertas de la ley, siempre abierta, por el solo hecho de preguntar. El paso del hecho al acontecimiento depende de la de(su)posición del sujeto supuesto al saber y del percatarse allí mismo que la pregunta (puerta) se encuentra articulada (abierta) aunque no es necesariamente articulable; pero no nos adelantemos.

Un acontecimiento, un múltiple que se nombra a sí mismo al decir de Badiou (1999), rompe esa ficción (fixion) imaginaria que mide y valora lo que la ley cuenta; dicho acontecimiento se sirve - y allí deviene sujeto - de la ley misma como diferencia pura (no cualificada) para nombrarse en acto por fuera de la norma y de las interpretaciones válidas (sensatas). Voy a decir más: el acontecimiento es la ley misma en su pura diferencia, es la torsión sobre sí del efecto-ley en tanto real-simbólico irreductible a la norma (estado ${ }^{6}$ ).

Encuentro el índice que me habilita a forzar tal enunciado en dos lugares un tanto paradójicos del pensamiento de Alain Badiou. Primero, en la explicación de por qué el múltiple genérico que es, en efecto, una verdad pertenece a la situación aún sin ser contado en ella, pues es un múltiple sin más predicado que su sola pertenencia (Badiou, 1999: 376). Esto resulta extraño si uno se ha habituado a considerar que a cada situación sólo le pertenece lo que es contado-por-uno, precisamente por ser discernido en ella a través del lenguaje que le es propio. El asunto aquí es que las dos cuentas (estructura/ley y metaestructura/norma) se dan siempre en simultaneidad, van juntas, y el acontecimiento es justamente su dislocación: lo que permite separar las dos

6 Badiou llama «estado de la situación» a la metaestructura, representación o cuenta-de-la-cuenta; mientras que «situación» es equivalente a presentación, estructura y cuenta-por-uno. Estos dos operadores de cuenta meta-ontológicos derivan de la distinción conjuntista entre pertenencia e inclusión. Véase el capítulo 8 de El ser y el acontecimiento.

7 Teorema de la teoría de conjuntos por el cual se deduce que las partes de un conjunto (o la inclusión) exceden a los elementos (pertenencia). Meditación 7 de El ser y el acontecimiento. 
modalidades de cuenta y dar lugar así al múltiple que se presenta en su presentación; este efecto de des-estructura o desdoblamiento no es para mí otra cosa que el mismo efecto de la ley en torsión sobre sí. Segundo, en la extraña afirmación de que el orden acontecimental es mucho más elemental y riguroso que el orden estatal (normal). Por supuesto, esto es así porque el estado de la situación es excesivo por definición - según el teorema del punto de exceso ${ }^{7}$ - y nunca se ajusta lo suficientemente a la estricta ley de la diferencia qua diferencia. Por el contrario, el acontecimiento lejos de ser caótico es el acto mismo de la ley sin ningún atenuante ni predicado cualificador; de ahí su lógica implacable («violencia mesiánica» en términos benjaminianos). Y la actualización de la ley, su despeje normativo/interpretativo, acontece por la efectuación de un nombre propio. No hay acontecimiento más que por su nominación suplementaria. El nombre propio rompe el cierre dogmático (naturalizado) de una identidad para forzar la pertenencia de nuevos términos incontados bajo el cierre ficcional de la ley, lo cual da lugar a un proceso de subjetivación; así lo piensa Badiou:

La subjetivación, configuración singular de una regla, subsume al Dos que ella es en la ausencia de significación de un nombre propio. San Pablo para la Iglesia, Lenin para el Partido, Cantor para la ontología, Schoenberg para la música, pero también Simon, Bernard o Claire, si ellos declaran un amor: son designaciones a través de lo uno de un nombre propio, de la escisión subjetivadora entre el nombre de un acontecimiento (muerte de Dios, revolución, múltiples infinitos, destrucción del sistema tonal, encuentro) y la puesta en marcha de un procedimiento genérico (Iglesia cristiana, bolchevismo, teoría de los conjuntos, serialismo, amor singular) ${ }^{8}$.

El acontecimiento que da lugar a un proceso de subjetivación de tal índole es, por supuesto, contingente. Y si bien, como dice Elías Palti, «todas las filosofías políticas modernas, incluido el marxismo, parten de la base de la contingencia de los fundamentos de todo orden ${ }^{9}$, el modo de tratar con este resto irreductible a lo simbólico, que es propiamente lo Real (como reverso innombrable de la ley), marca diferentes posiciones teóricas y por supuesto también ético-políticas. Se puede seguir así una especie de progresión en la elucidación crítica que cada una de estas posiciones teóricas va a desplegar en torno a la orientación por lo Real del orden discursivo, que - sobre todo a partir del giro lingüístico - ya no será identificado plenamente con la realidad, producida la ruptura definitiva con la búsqueda de adecuación entre representación y cosa, sujeto y objeto, etc.

No pretendo hacer un análisis minucioso de sus respectivas posiciones sino simplemente indicar la radical diferencia que se produce en torno al mis-

8 Badiou, A., El ser y el acontecimiento, op. cit., p. 433.

9 E. J. Palti, Verdades y saberes sobre el marxismo. Reacciones de una tradición política ante su crisis, Buenos Aires, Fondo de Cultura Económica, 2005, p. 131. 
mo núcleo problemático (la contingencia de lo real y de los órdenes discursivos).

Por ejemplo: los teóricos de las políticas del consenso y la comunicación como Habermas, Apel y Rawls, buscan reducir al mínimo la equivocidad que induce en los «juegos de lenguaje» (o discursos) lo Real innombrable, al intentar definir de la manera más unívoca y clara posible (vía regia: el derecho) las reglas que regulan los «actos comunicativos»; lo que constituye una actitud de verdadero rechazo (verwerfung ${ }^{10}$ ), de «no querer saber nada de eso», ante este Real que retorna ineludiblemente ${ }^{11}$. Se opera así una suerte de «exclusión externa» de lo Real, que no impide su retorno sintomático cada vez más violento en las actuales democracias liberales, tal como sucede por ejemplo con fenómenos socio-políticos como el resurgimiento de los fundamentalismos nacionalistas, los sans papiers, etc.

El «deconstruccionismo», por su parte, reduce todo orden discursivo a una mera ficción, al develar la radical contingencia de sus fundamentos y situar ese vacío central que Derrida llama Khora, operación que resitúa lo Real en una relación, ahora, de "inclusión externa» con la estructura discursiva; sin embargo no se propone una acción política concreta. En cambio Laclau y Mouffe, desde el «marxismo post-estructuralista» ${ }^{12}$, realizan la misma operación deconstructiva pero señalan la importancia de la «articulación», es decir, de cómo ese vacío central propio de todo orden discursivo - y que es propiamente el lugar del universal - debe ser ocupado contingentemente por un particular en representación de la totalidad que lo excede, lo que configura así una práctica hegemónica; por lo tanto toda práctica política en una democracia radical no podría evitar esta representación parcial y distorsionada de una totalidad imposible, y a su vez la elucidación - y sostenimientode esta verdad la define como tal. En la misma vertiente de pensamiento Zizek postula — en una lectura más ceñida a Lacan — que no basta con la articu-

10 Este término es particularmente desarrollado por Lacan en relación a la psicosis, véase en los Escritos 1 y 2, pp. 5, 346, 349, 371, 372, 539, 540, 558, 559, 562, 563, 649-650, 853. Principalmente en «De una cuestión preliminar a todo tratamiento posible de la psicosis», en Jacques Lacan, Escritos 1 y 2, Siglo XXI, Bs.As., 2003, p. 513.

11 Dardo Scavino escribe: «Al identificar la democracia con el Estado de derecho, las teorías neo-contractualistas de Habermas, Apel o John Rawls, confunden la política con la resolución jurídica de los conflictos y crean, a su manera, otra forma de totalitarismo: pensar que todos los litigios pueden resolverse por la vía de la discusión razonable entre las partes, doctrina en la que se basan las actuales democracias liberales. Este totalitarismo aparece bajo la forma de un ideal de transparencia gracias al cual todas las "opacidades" de la comunicación serían finalmente eliminadas.» (Dardo Scavino, La filosofía actual. Pensar sin certezas, Paidós postales, 1999, p. 113.)

12 Elías Palti escribe: «El marxismo post-estructuralista propondrá sin embargo, ir más allá de la fase deconstruccionista e intentar pensar, a su vez, cómo se constituyen nuevos horizontes de sentido a partir de dicho vacío, esto es, la serie de operaciones que dan lugar a los procesos de subjetivación.» (Elías José Palti, Verdades y saberes sobre el marxismo. Reacciones de una tradición política ante su crisis, op. cit., p. 106. 
lación del particular en el lugar vacío del universal (lo que al ser una operación imposible y necesaria a la vez provocaría una actitud cínica por parte de los sujetos comprometidos en este modo de práctica política), sino que es necesario introducir un tercer término: lo individual («el exceso sintomático que socava ese contenido hegemónico») ${ }^{13}$, es decir, que la práctica política coincidiría con «identificarse al síntoma» social (el proletariado en el marxismo tradicional) en ruptura con la dialéctica simple del particular-universal. El problema reside en especificar cómo se evitan las burdas identificaciones imaginarias, imitativas, y los discursos demagógicos, por ejemplo, al reintroducir cierta «sustancialización» del agente hegemónico (identificado con el proletariado, discernido por rasgos económicos).

\section{II}

Rancière, en Los bordes de lo político (2007), trabaja precisamente la diferencia entre dos modalidades del Uno que intentan regular la ley: a) un ordenamiento político ligado a la gestión y administración de bienes y personas (una equivalencia generalizada de Unos contables), y b) el retorno de una conformación política arcaica basada en el odio y el temor al Otro (reunida por el Uno que excluye). A mi modo de ver, sin embargo, no logra distinguir muy bien, bajo esta oposición, la ruptura con el Uno imaginario/simbólico tanto del ordenamiento de clases (maquinalidad) como de la jauría temerosa (animalidad), del Uno simbólico/real que es la ley como pura diferencia de sí, y que es, según mi tesis, lo que permite nombrarse más allá de lo significado/valorado hasta ese momento. Pues si no fuese así quedaríamos ante la pura dispersión de lo real, el horror crudo de la disolución psicótica.

Sin embargo, para Rancière, lo que resiste tanto la reducción de lo político al mero ordenamiento social (gestión) como la reunión temerosa por el odio al Otro (comunidad), es el démos como afirmación de una parte excesiva, suplementaria, ya no Uno sino Dos: «el poder reunidor-divisor del primer múltiple, el poder del dos de la división» (Rancière, 2007: 57). Para nosotros, en cambio, el dos heterogéneo sólo puede producirse en el amor, mientras que la política consiste en la reunión de una multiplicidad infinita bajo el trazo de una marca acontecimental que le pertenece, sin exclusión alguna. Este proceder se inscribe en una lógica del no-Todo que ni siquiera los filósofos lacanianos (nueva especie que coincide con su género) han osado desarrollar - aunque parece que Copjec lo está intentando ${ }^{14}$.

13 Slavoj Zizek, El espinoso sujeto. El centro ausente de la ontología política, Bs. As., Manantial, 2001, p. 194.

14 Véase por ejemplo: Copjec, J., Imaginemos que la mujer no existe. Ética y sublimación, Fondo de Cultura Económica, Bs. As., 2006. Y Copjec, J., El sexo y la eutanasia de la razón, Paidós, Bs. As., 2006. 
Entonces, ni animalidad amorfa de una jauría atemorizada y odiosa ni maquinalidad equivalencial y gozosa de un orden establecido, el cuerpo humano, el cuerpo esencialmente político, se constituye deshaciendo toda figura de unidad, de exclusión/inclusión y jerarquía; se constituye, así, polemizando y soportando la división incesante que es en sí la efectuación afirmativa de la ley (el deseo): «la lucha de clases ha proclamado e instalado en el corazón mismo del conflicto democrático el poder humanizante de la división» (ibid.). ¿Por qué sería humanizante (subjetivante) la división per se?

El nombre desprestigiado que hay que reinvestir en el estado actual de los asuntos políticos, nos sugiere Rancière, es la «lucha de clases». Ahí está pues: «la clase que diluye todas las clases» (al decir de Marx) ¡Es la ley misma! Si se cuenta se anula ¿Cómo nombrarla entonces, se pregunta Rancière - como todo el mundo-, si hacerlo disuelve todas las clases y al mismo tiempo pareciera fijar cierta «sustantividad» (retorno del Uno)? Lo mismo que intentaba articular Zizek en El sublime objeto de la ideología (2005), situándose entre la teoría de la hegemonía de Laclau-Mouffe y la polémica descriptivismo/antidescriptivismo: «¿cómo formulamos el papel determinante de un terreno particular sin caer en la trampa del esencialismo? Mi tesis es que el antidescriptivismo de Saúl Kripke nos proporciona las herramientas conceptuales para resolver este problema» (Zizek, 2005: 127). Y desembocaba así en el après coup lacaniano por el cual es, en definitiva, el efecto retroactivo de la nominación lo que constituye el objeto (en este caso la «lucha»); es decir, la intervención efectiva que sobreinviste ese «plus» inasible que es el objeto «más que en él mismo» ${ }^{15}$. Otra vez: la ley qua diferencia; ese suplemento inherente a la ley misma (su reverso) que le impide anularse. Entra en juego aquí la diferencia entre determinante/dominante que trabajan Althusser y Badiou en torno a la instancia económica ${ }^{16}$ y la posibilidad $-\mathrm{O}$ no- de abrir el pensamiento a múltiples intervenciones en lugar de fijar un solo sitio privilegiado para nombrar lo real. Lo veremos junto a Agamben y los múltiples modos de suspender la máquina antropológica.

15 Ese «en él más que él mismo», esa especie de «aura» puede rastrearse en lo que señala también Agamben respecto al método de Benjamin: «Aquello que la filología ha recogido así en su cerrada facticidad debe ser sin embargo construido desde la perspectiva histórica, con una operación que Benjamín define como una Aufhebung de la filología. Pero las líneas de fuga de esa perspectiva no se hallan en el "proceso global" ni en la "buena teoría especulativa", sino "en nuestra propia experiencia histórica". Sólo ésta tiene la capacidad de animar el objeto, despertándolo de la mítica rigidez filológica.» (Infancia e historia, p. 182) Por supuesto, las dos primeras alternativas entrecomillas que son descartadas pertenecen a Adorno mientras que la tercera elegida — la animación objetal— pertenece a Benjamin.

16 Badiou, A. y Althusser, L., «Materialismo histórico y materialismo dialéctico», en Cuadernos de Pasado y Presente /8, Córdoba [1967]. He trabajado sobre ello en: Farrán, R., «La problemática circularidad de todo (re)comienzo materialista. Spinoza, luego Badiou». $\mathrm{Pu}-$ blicado en A Parte Rei, Revista de Filosofia, mayo de 2009 ISSN 1137-8204. 
Agamben en su libro Lo abierto (2007), por ejemplo, comienza analizando una Biblia hebrea del siglo XIII donde se representa a los justos con cabezas animalescas durante el banquete mesiánico, y adelanta la siguiente conjetura: «No es imposible, por lo tanto, que atribuyendo una cabeza animal al resto de Israel, el artista del manuscrito de la Ambrosiana haya querido significar que, en el último día, las relaciones entre los animales y los hombres tendrán una nueva forma y el hombre mismo se reconciliará con su naturaleza animal.» (Agamben, 2007: 12) Esta hipótesis de reconciliación será interrogada a través de un recorrido sino exhaustivo al menos bastante ilustrativo sobre la historia de la máquina antropológica que determina en cada época qué es humano y qué animal.

Para Badiou, en cambio, la animalidad es el estatuto «normal» de los hombres en tanto sólo se dedican a reproducir sus vidas, a sobrevivir, sin participar de ningún «procedimiento genérico de verdad», es decir, sin devenir sujeto y a la postre «inmortal» ${ }^{17}$. Es decir, que de algún modo el animal/máquina es producto de la reducción del hombre a lo contable.

La animalidad del hombre es, en este sentido, lo que ya señalaba Kojève en los 50 refiriéndose al estado posthistórico que había alcanzado la humanidad, cuyo ejemplo cada vez más expansivo lo brindaba por entonces EEUU y su American way of live. Sin embargo, parece que «el porvenir es largo» (como el título que lleva la autobiografía de Althusser), pues al final de la historia resisten aún dos figuras subjetivas según Kojève-Bataille: el snob japonés que se empeña en seguir rituales vacíos como la ceremonia del té o el arreglo floral y el sujeto acéfalo cuya «negatividad sin empleo» busca su gasto a través del juego, la risa, el erotismo.

Para Agamben la diferencia crucial que determina la gran mayoría de los problemas ético-políticos contemporáneos continúa pasando, principalmente, por la distinción entre animal y hombre. «Como si la determinación de la frontera entre lo humano y lo animal no fuera simplemente una cuestión más sobre la cual discuten filósofos y teólogos, científicos y políticos, sino una operación metafísico-política fundamental, y en la cual sólo algo así como un "hombre" puede ser decidido y producido.» (ibid.: 47) En definitiva, lo que va a señalar el filósofo italiano es que persiste aún, como legado aporético del idealismo filosófico, una tensión irreductible entre animalidad y humanidad que divide y tensiona al cuerpo posthistórico del hombre y que es lo que hay que pensar o producir en la actualidad (ibid.: 28).

Se podría entrever que las notas que toma Agamben de Linneo, por ejemplo, concuerdan en cierta forma con la caracterización genérica de la humanidad que sostiene Badiou: no hay diferencia específica que caracterice a lo humano, se deviene tal a partir del pensamiento mismo, del reconocimiento de

17 Esta temática está desarrollada sobre todo en su libro sobre la ética. 
sí (homo sapiens). O como diría Pascal: lo humano supera infinitamente lo humano, está en exceso sobre sí. Y aquí aparece la mención a la máquina antropológica: «Homo sapiens no es, por lo tanto, ni una sustancia ni una especie claramente definida; es, más bien, una máquina o un artificio para producir el reconocimiento de lo humano.» (ibid.: 58) En términos de Linneo: El humano es el mono que se reconoce a sí mismo como no siendo, mientras que el que no lo hace es un mono hecho y derecho. La complejidad introducida por Badiou pasaría, más bien, por los distintos dispositivos a partir de los cuales el hombre, aun no siendo en situación, adviene en nombre de un acontecimiento suplementario a ella (a su animalidad o maquinalidad de base). Estos dispositivos humanizadores o procedimientos genéricos, como él les llama, son múltiples y en lugar de distinguir, excluir y clasificar, indisciernen, conectan y generan.

A ello se aproxima Agamben cuando, luego del repaso histórico por las distintas variantes de la máquina antropológica, concluye con la posibilidad disponible para nuestra época posthistórica de suspender su funcionamiento.

«En nuestra cultura el hombre - lo hemos visto- ha sido siempre el resultado de una división, y, a la vez, de una articulación de lo animal y lo humano, en la cual uno de los dos términos de la operación era también lo que estaba en juego. Volver inoperante la máquina que gobierna nuestra concepción del hombre significará, por lo tanto, ya no buscar nuevas articulaciones —más eficaces o más auténticas—- sino exhibir el vacío central, el hiato que separa - en el hombre - el hombre y el animal, arriesgarse en este vacío: suspensión de la suspensión, shabbat tanto del animal como del hombre.» (ibid.: 176).

Interpreto dicha suspensión como una producción efectiva de vacío y no como mera «exhibición», pues sólo en la retroactividad de una intervención efectiva el vacío habrá sido localizado como tal y circunscrito; no más distribución reglada de qué es hombre y qué animal, sino indistinción, sustracción de rasgos identificatorios, es decir, producción de lo genérico. Por supuesto hay separación, suspensión, ruptura con las máquinas clasificatorias y sus modalidades sapientes, pero también hay conexiones y articulaciones imprevistas entre múltiples heterogéneos, dispares, singulares. Ello da qué pensar y nos pone en acto tras la suspensión de la norma.

Para Badiou las verdades o procedimientos genéricos ya no son estatales, no nos gobiernan; al contrario, proceden agujereando los saberes y las distinciones establecidas por los estados propios de cada situación. En el vacío los rasgos se indistinguen, tal como en el cuadrante lógico de Peirce la universal afirmativa (todos los trazos son verticales) y la negativa (ningún trazo es vertical) coinciden en el espacio vacío; por eso Lacan lo utiliza como operador indistinto del sujeto. Podríamos afirmar entonces que la división subjetiva producida por el significante — según lo formula el psicoanálisis — no permi- 
te distinguir los rasgos animales, por una parte, de los rasgos humanos por otra, es el vacío mismo producido por un corte significante (la ley del deseo).

Podemos entender entonces la filosofía o el campo de producción teórica como un espacio de cruce y entrelazamiento de múltiples procedimientos genéricos, de múltiples modos de suspender las maquinarias antropológicas que aún siguen funcionando.

Incluso podríamos encontrar una alusión a este modo de entender la práctica teórica en un texto temprano de la producción de Agamben, Infancia e historia [1978] (2007). Refiriéndose a la diferencia entre estructura y superestructura en la teoría marxista dice:

La praxis en efecto no es algo que necesite de una mediación dialéctica para representarse luego como positividad bajo la forma de superestructura, sino que desde un principio es "verdaderamente lo que es», desde un principio posee integridad y concreción. Si el hombre se revela «humano» en la praxis no es porque, además de efectuar en primer lugar una actividad productiva, luego transpone y desarrolla esa actividad en una superestructura y entonces piensa, escribe poemas, etc.; si el hombre es humano, si es un Gattungswesen, un ser cuya esencia es el género, su humanidad y su ser genérico deben estar íntegramente presentes en el modo en que produce su vida material, es decir, en la praxis. Marx anula la distinción metafísica entre animal y ratio, entre naturaleza y cultura, entre materia y forma, para afirmar que en la praxis la animalidad es la humanidad, la naturaleza es la cultura, la materia es la forma. Si admitimos esto, la relación entre estructura y superestructura no puede ser ni de determinación causal ni de mediación dialéctica, sino de identidad inmediata (Agamben, 2007: 179).

Ahora bien, tal «identidad inmediata» nunca está dada por la simple evidencia ni tampoco sería verificable en términos de una metateoría o un metalenguaje, al contrario, es lo que hay que producir cada vez en una intervención efectiva.

\section{IV}

Esta perspectiva que venimos desarrollando es por otra parte absolutamente compatible y composible ${ }^{18}$ con la verdad de la democracia tal como la plantea Jean Luc Nancy. Lo cito in extenso dada la riqueza de su planteamiento:

La democracia (re)engendra al hombre, declara Rousseau. Abre con nuevos bríos la destinación del hombre y del mundo con él. La «política» ya no puede dar la medida ni el lugar de esa destinación o destinerrancia (Derri-

18 Deriva de «composibilidad», traducción del neologismo compossibilité empleado por Badiou para dar cuenta de la tarea filosófica: componer/hacer posible. 
da). Debe permitir su puesta en juego y asegurar sus lugares múltiples, pero no la asume. La política democrática es, pues, política alejada de la asunción. Pone término a toda especie de «teología política», sea teocrática o secularizada, Postula en consecuencia como axioma que no todo (ni el todo) es política. Que todo (o el todo) es múltiple, singular-plural, inscripción en fragmentos finitos de un infinito en acto («artes», «pensamientos», «amores», «gestos», «pasiones» pueden ser algunos de los nombres de esos fragmentos) (Nancy, 2009: 57).

El axioma de que no todo es política es aquí fundamental. La democracia definida como lugar donde tengan lugar justamente múltiples experiencias finitas del infinito actual; donde las diversas nominaciones modulen su tiempo; donde inventen y se inventen sin subsumir o subsumirse a los otros, sin jerarquías ni telos de ningún tipo. Si bien esto puede generar una imagen de dispersión, de caos o eclecticismo, la existencia misma del espacio democrático como lugar de composibilitación que impide las suturas abre, así, las vías de cruce y transferencias no prescriptivas, producidas al azar, entre los diversos procedimientos genéricos de invención. En definitiva, para suspender las maquinarias antropológicas no basta con mostrar el vacío, hay que reinventar lugares, excederlos, atravesarlos, desbordarlos continuamente mediante la invención de nuevos nombres y procedimientos.

Además no podemos dejar pasar por alto, en una suerte de constatación performativa, que tal maquinaria antropológica no funciona sino en virtud del lenguaje mismo. Algunos de nuestros autores se percatan, en mayor o menor medida, acerca del poder de las nominaciones y clasificaciones que aquél habilita; algunos incluso proponen volver el lenguaje sobre sí mismo para deconstruirlo; otros interrumpirlo con matemas o poemas; otros cortarlo directamente en un acto sin garantías de significación (escrituras, políticas, gestos). Cada quien hace lo que puede en este inhóspito ámbito inquietantemente familiar.

Para finalizar, una cita de Roland Barthes:

Algunos esperan de nosotros, intelectuales, que actuemos en toda ocasión contra el Poder; pero nuestra verdadera guerra está en otra parte, está contra los poderes; no se trata de un combate fácil porque, plural en el espacio social, el poder es, simétricamente, perpetuo en el tiempo histórico: expulsado, extenuado aquí, reaparece allá; jamás perece: hecha una revolución para destruirlo, prontamente va a revivir y a rebrotar en el nuevo estado de cosas. La razón de esta resistencia y de esta ubicuidad es que el poder es el parásito de un organismo transocial, ligado a la entera historia del hombre, y no solamente a su historia política, histórica. Aquel objeto en el que se inscribe el poder desde toda la eternidad humana es el lenguaje o, para ser más precisos, su expresión obligada: la lengua. El lenguaje es una legislación, la lengua es su código. No vemos el poder que hay en la lengua porque olvidamos que toda lengua es una clasificación, y que toda clasificación es opresiva... (Barthes, 2004: 95). 
Nos restaría entonces pensar lo genérico más acá de todo lenguaje y de su correlativa opresión clasificatoria. Lo universal como no-Todo y no sólo como síntoma emergente ante el exceso de totalización. Pensar de este modo la destotalización por el lado de la inconsistencia (o paraconsistencia) en lugar de hacerlo por el lado de la incompletitud: no sólo la negatividad o imposibilidad (lo real como «imposible de escribirse») sino la potencia o posibilidad (lo real como «lo que resta escribirse») que se abre en la contingencia de cada acto de invención. Ésta sería la dimensión propiamente ética del discurso que aquí sostenemos.

\section{BIBLIOGRAFÍA}

Agamben, Giorgio (2007 [1978]). Infancia e historia, Buenos Aires, Adriana Hidalgo.

Agamben, Giorgio (2007). Lo abierto, Buenos Aires, Adriana Hidalgo.

BAdiou, Alain y Althusser, Louis (1967). «Materialismo histórico y materialismo dialéctico», en Cuadernos de Pasado y Presente /8, Córdoba.

BADIOU, Alain (1999). El ser y el acontecimiento, Buenos Aires, Manantial.

BARThes, Roland (2004). Lo neutro, Buenos Aires, Siglo XXI.

COPJEC, Jean (2006). Imaginemos que la mujer no existe. Ética y sublimación, Buenos Aires, Fondo de Cultura Eeconómica.

Copjec, Jean (2006). El sexo y la eutanasia de la razón, Buenos Aires, Paidós.

FARRÁN, Roque (2009). «La problemática circularidad de todo (re)comienzo materialista. Spinoza, luego Badiou». Publicado en A Parte Rei, Revista de Filosofía, mayo, ISSN 1137-8204.

NANCY, Jean-Luc (2009). La verdad de la democracia, Buenos Aires, Amorrortu.

PALTI, Elías José (2005). Verdades y saberes sobre el marxismo. Reacciones de una tradición política ante su crisis, Buenos Aires, Fondo de Cultura Económica.

RANCIÈRE, Jacques (2007). En los bordes de lo político, Buenos Aires, La Cebra. ZIZEK, Slavoj (2005). El sublime objeto de la ideología, Buenos Aires, Siglo XXI. 